\title{
Screening of Human Phycotoxin Poisoning Symptoms in Coastal Communities of Nigeria: Socio-Economic Consideration of Harmful Algal Blooms
}

\author{
M. O. Kadiri' ${ }^{1}$ E. M. Denise ${ }^{2}$, J. U. Ogbebor ${ }^{3 *}$, A. O. Omoruyi ${ }^{4}$, S. Isagba', S. D. Ahmed ${ }^{5}$, \\ T. E. Unusiotame-Owolagba ${ }^{6}$
}

\author{
${ }^{1}$ Department of Plant Biology and Biotechnology, University of Benin, Benin, Nigeria \\ ${ }^{2}$ Department of Botany \& Ecological Studies, University of Uyo, Uyo, Nigeria \\ ${ }^{3}$ Department of Environmental Management and Toxicology, University of Benin, Benin, Nigeria \\ ${ }^{4}$ Department of Botany, Faculty of Life Sciences, Ambrose Alli University, Ekpoma, Nigeria \\ ${ }^{5}$ Department of Medicine, Irrua Teaching Hospital, Irrua, Nigeria \\ ${ }^{6}$ Department of Marine Environment \& Pollution Control, Nigeria Maritime University, Okerenkoko, Warri South-West L. G. A., \\ Delta State, Nigeria \\ Email: ^mokadiri@uniben.edu, solosagba@yahoo.com, mukoroemmanuel01@gmail.com, jeffrey.ogbebor@uniben.edu, \\ osasere.omoruyi@aauekpoma.edu.ng,ahmeddaz@yahoo.com,classicpals@gmail.com
}

How to cite this paper: Kadiri, M.O., Denise, E.M., Ogbebor, J.U., Omoruyi, A.O., Isagba, S., Ahmed, S.D. and Unusiotame-Owolagba, T.E. (2020) Screening of Human Phycotoxin Poisoning Symptoms in Coastal Communities of Nigeria: Socio-Economic Consideration of Harmful Algal Blooms. Journal of Environmental Protection, 11, 718-734.

https://doi.org/10.4236/jep.2020.119044

Received: July 8, 2020

Accepted: September 11, 2020

Published: September 14, 2020

Copyright ( 2020 by author(s) and Scientific Research Publishing Inc. This work is licensed under the Creative Commons Attribution International License (CC BY 4.0).

http://creativecommons.org/licenses/by/4.0/

\begin{abstract}
A screening of human phycotoxin poisoning symptoms was done in the coastal communities of Nigeria, every quarter for one year, using structured questionnaires. A multi-stage sampling technique consisting of cluster, snowballing, convenience purposive and random sampling was applied in the study. Based on the responses, a total of $17 \mathrm{Harmful}$ algal toxin-related poisoning symptoms were recorded from respondents, who experienced these symptoms from seafood consumption. The symptoms were Balance difficulty, Breathing difficulty, Burning sensation, Chills, Confusion, Diarrhea, Dizziness, Body itching, Headache, Memory loss, Mouth tingling, Muscle pain, Nausea, Rashes, Abdominal pain, Tiredness and Vomiting. These could be grouped into five categories of diseases namely, Respiratory, Gastrointestinal, Neurological, Dermatological, and Musculo-Skeletal symptoms. The most commonly experienced symptoms were vomiting (24\%), mouth tingling (21\%), Nausea (14\%), diarrhea (11\%), headache (10\%), tiredness (9\%) and body itching (8\%) and the least were muscle pain, rashes, confusion, chills, dizziness, balance difficulty burning sensation, breathing difficulty and abdominal pain. Statistical analyses revealed a nexus and significant relationship between visible symptoms and: seafood; season; water colour; habitats/environment of dead sea-
\end{abstract}


food and age of respondents. Symptoms enlisted are reminiscent of harmful algal blooms, with grave consequences for public health, commercial fisheries, recreation, tourism, monitoring/management. Therefore, preventive measures, requiring routine monitoring of water bodies, coupled with greater public awareness is suggested for early detection of occurrence of toxin-producing symptoms.

\section{Keywords}

Coastal, HABs Symptoms, Nigeria, Phycotoxins, Socio-Economic

\section{Introduction}

Harmful algal blooms (HABs) are increasing in frequency and intensity in coastal regions globally [1] [2]. These harmful algal blooms are undergoing geographical expansion via a myriad of mechanisms such as natural environmental factors (hurricanes, earthquakes, ideal growth and transport conditions and physiological adaptation of bloom-forming species); anthropogenic activities (increased eutrophication, marine transportation, ballast water transport aquaculture development); and climate change [3] [4]. Consequent upon these, the proliferation of HABs has significant socioeconomic and ecological costs, which impact drinking water, fisheries (massive fish-kills, shellfish poisoning), wildlife mortalities, human illness and death, agriculture, tourism, real estate, water quality, food web resilience and habitats, and contribute to anoxia [5].

The consequences of harmful algae include intoxication of shellfish tissue causing several illnesses or even death of marine wildlife and people as well as depriving citizens of vital recreational opportunities in addition to hampering the supply of drinking water. Toxic blooms are similarly becoming more frequent, potentially impacting public health, regional economies, and lifestyles of citizens who use such water bodies [6]. The risk of HAB-related illness is further exacerbated by quest and preference for healthy heart diets (seafood), insurgence to travel to coastal destination, increase in coastal urban population coupled with marine recreation (yachting, boating, swimming, surfing, sports, etc.) [4]. HABs are characterized by patches of discolored water, dead or dying fish, and respiratory irritants in the air [7].

In Nigeria coastal waters, studies exist on algal toxin profiles [8], harmful dinoflagellates and toxigenic diatoms [9] [10], harmful algal poisoning syndromes [11], toxin-producing algae modelling [12] among others. This report aims to examine human health symptoms of harmful algae in coastal communities of Nigeria. This is the first study of this nature in Nigeria, West Africa.

\section{Study Area}

The study was carried out in the coastal area of Nigeria, situated in the Atlantic Ocean in Gulf of Guinea, in the Bight of Bonny to the east and Bight of Benin to 
the west in Nigerian coast. The study area covered 10 locations (Cross River, Akwa Ibom, Rivers, Bayelsa, Delta, Ondo, Ogun, Lagos, Lekki, Bar beach and Badagry (Figure 1) of Nigeria, lying between longitudes $3^{\circ} 24^{\prime}$ and $8^{\circ} 19^{\prime} \mathrm{E}$ and latitude $4^{\circ} 58^{\prime}$ and $6^{\circ} 24^{\prime} \mathrm{N}$ along the Nigerian coastline [13]. The Nigerian coastal states are divided into two regions namely; South-South region and the South-West region according to their geographic position. The South-South consists of five states namely; Cross River, Akwa Ibom, Rivers, Bayelsa and Delta, while South-West comprises three states [Ondo, Ogun, Lagos (Lekki, Bar beach, Badagry)]. Climatically, there are two main seasons in the area, namely the rainy (wet) season spanning from May to October and dry season from November to April. The coastal area is humid with a mean average temperature of $24^{\circ} \mathrm{C}-32^{\circ} \mathrm{C}$ and an average annual rainfall ranging between $1500-4000 \mathrm{~m}$ [14].

\section{Materials and Methods}

This research was both an exploratory and a survey study that sought to examine the knowledge and attitude of persons who eat seafood. The research is a novel one and prior relevant information is not available. Therefore exploratory scheme was used to gather information about the subject matter in the field. For this, the primary method of observation was adopted. The purpose was to obtain information that would require further analysis. The exploratory scheme was used to identify likely respondents that would be willing to participate in the

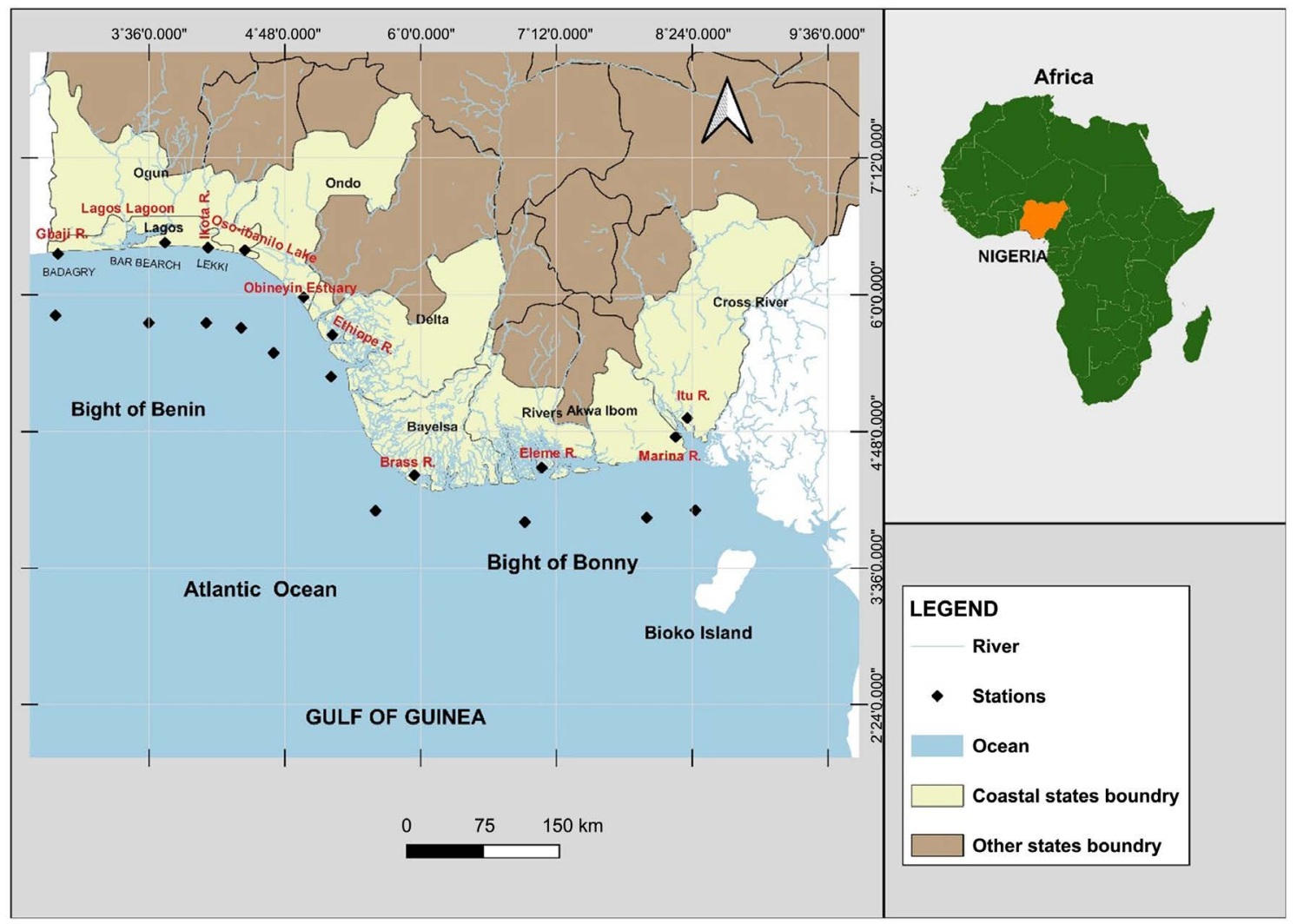

Figure 1. Map of study area: coastal area of Nigeria. 
survey. A survey study is the systematic gathering of information from respondents for the purpose of understanding or predicting some aspect of the behaviour of the population of research. However one of the features of this is that it involves obtaining data from respondents with the aid of questionnaires or an interview guide [15]. Hence the qualitative study made use of the structured questionnaire in eliciting the required response from the respondents.

The research was a seasonal study that was carried out by 4 research teams, consisting of an average 6 members each, within a year period and at different seasons: Dry-wet (March, 2014), Wet (July, 2014), Wet-dry (October, 2014) and Dry (January, 2015). The study was conducted within the coastal region of southern Nigeria, and these include; Cross River, Akwa Ibom, Rivers, Bayelsa, Delta, Ondo, Ogun and Lagos States including Lekki, Bar Beach and Badagry. It was a onetime survey in each season as the questionnaires were administered on face to face approach, and this made the willing respondents to give answers to the questions asked in each of the questionnaire administered.

The sampling technique used was a multi-stage sampling consisting of cluster, snowballing, random sampling, convenience and purposive sampling. The cluster method was used in grouping the respondents by the state of residence, from which in some states purposive sampling was used. This is because some respondents who were interviewed had strong knowledge of the study objective and they were consulted. For others, the respondents were consulted at random and some respondents referred (Snowballing) the research team to other respondents residing in same residence after being granted interview.

The convenience sampling method was used in some locations where the respondents are fishermen/women and were seen to be in a hurry to give answers and go to work. The proposed sample size for the study was 2000, however, due to the nature of the respondents, their residence and occupation/job, a total of 985 responded and copies of questionnaire were retrieved from the field and analyzed. The method of data analysis was both Univariate and Bivariate through the use of the statistical package of social science (SPSS). Simple frequency, percentage, charts and graphs were utilized in interpreting the results while the Chi-square $\left(\mathrm{X}^{2}\right)$ coefficients were used in testing the stated hypotheses.

\section{Results}

\section{Socio-Demographic Characteristics of Respondents}

In examining the socio-demographic characteristics of the respondents, it was discovered the dry season (January) and wet-dry season (October) were the period with the highest records $24.3 \%$ and $20.9 \%$ respectively. Badagry, Akwa Ibom, Ondo and Ogun were the major location with the highest respondents constituting $16.4 \%, 18.1 \%, 13.0 \%$ and $16.5 \%$ respectively. On personal attribute of the respondents, the study revealed that majority of the respondents were males, consisting $60.3 \%$ of the entire respondents, while $39.7 \%$ were females. In terms of religion, Christian made up $87.5 \%$ of the entire respondents, Muslims 
10.6\% while the African Traditional Worshippers were least, accounting for only $1.9 \%$.

On the occupation of the respondents, the study revealed that $27 \%$ of the entire respondents were traders, followed by students $(25.8 \%)$, farmers $(12.7 \%)$ fishermen (11.3\%) and Civil servants (10.3\%). Others include tailors, with $6.6 \%$, self-employed persons, $1.3 \%$ and others had less than $1 \%$ from the study. Among the respondents, the Yoruba's and the Ijaws had the highest ethnic group with $37.4 \%$ and $14.2 \%$ respectively, among others, the least of the ethnic groups the Ekom, Egbira, Ihan and Bokori, with less than 1\% each.

Figure 2 depicts the age brackets of respondents.

On the average, out of a total of 985, the respondents with the highest frequency are those within age bracket of 20 - 39 years constituting $43.1 .9 \%$ of the entire respondents, followed by 30 - 39 years (25.8\%), and <20 years (17.5\%), 40 - 49 years $(10.8 \%)$ while the least were the respondents within ages $\geq 50$ years with $2.8 \%$. On the basis of marital status, $53.5 \%$ and $43.8 \%$ of the respondents were married and single respectively, while $1.1 \%$ reported that they were separated More than half of the respondents (53.8\%) had Senior School Certificate (SSCE) qualifications as their highest qualification while $28.7 \%$ reportedly had a university degree.

\section{Symptoms experienced by coastal communities}

Seventeen harmful algal bloom toxins symptoms were recorded from respondents to the questionnaires administered in this study. Different respondents confirmed that they experienced these symptoms when they consumed some of

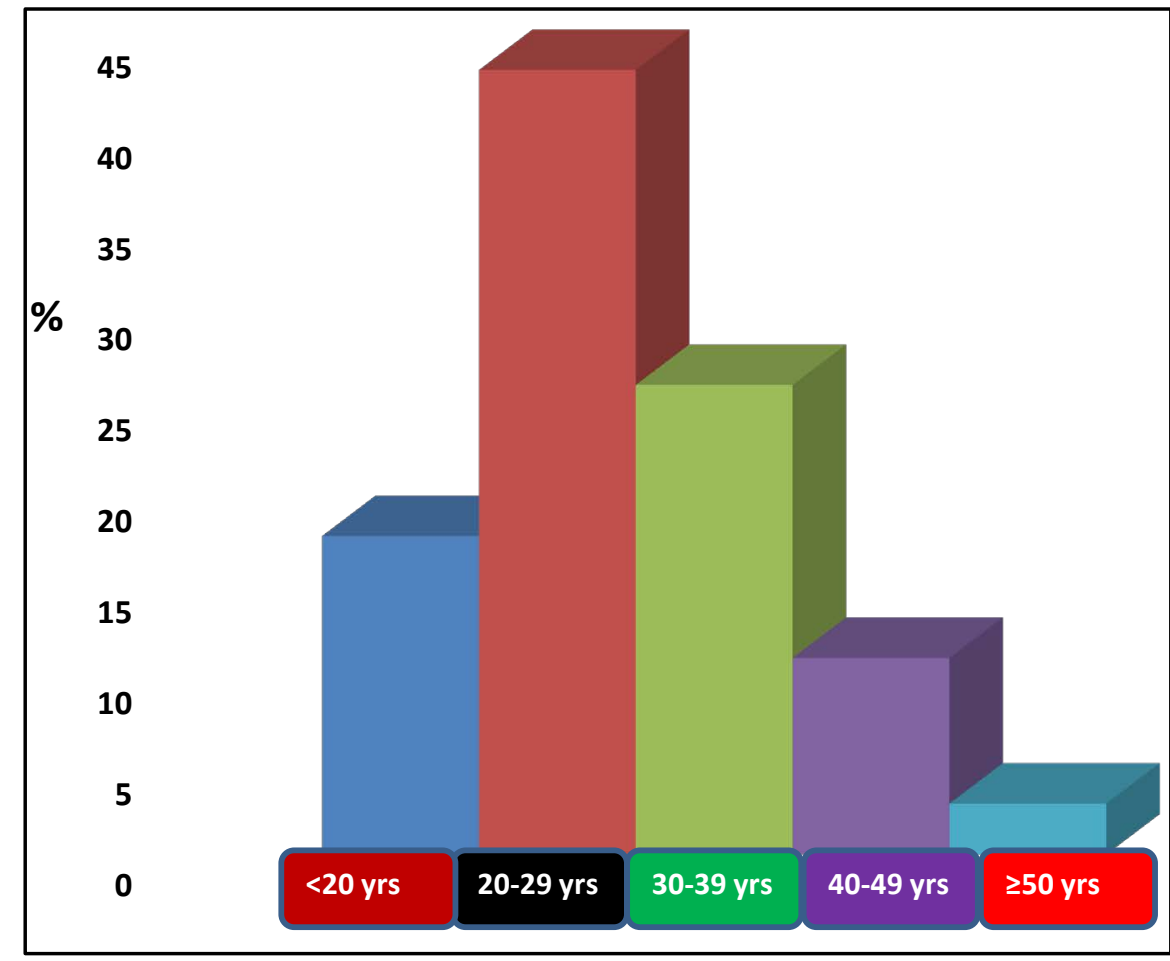

Figure 2. Percentage distribution of ages of respondents. 
the seafoods. The symptoms were: Balance difficulty, Breathing difficulty, Burning sensation, Chills, Confusion, Diarrhea, Dizziness, Body itching, Headache, Memory loss, Mouth tingling, Muscle pain, Nausea, Rashes, Abdominal pain, Tiredness and Vomiting. From the medical perspective, the 17 symptoms experienced by communities in the coastal areas can be organized into five groups of diseases namely Respiratory, Gastrointestinal, Neurological, Dermatological, and Musculo-Skeletal symptoms.

Other symptoms listed in the questionnaires were not experienced by respondents. Such symptoms were Double vision, Paralysis, Convulsion/Seizures and Hallucination. Some respondents claimed they did not experience any of the above symptoms. Out of those who experienced symptoms, the frequency of most prominent symptoms was computed and represented in Figure 3. The most frequent symptom was vomiting (24\%), closely followed by mouth tingling (21\%). Nausea was $14 \%$, diarrhea $11 \%$, headache $10 \%$, tiredness $9 \%$ and body itching $8 \%$.

Others occurring occasionally but in insignificant numbers include muscle pain, balance difficulty, burning sensation, breathing difficulty, dizziness and abdominal pain

\section{Seasonal occurrence of Symptoms.}

Figure 4 shows the season of occurrence of symptoms. Overall, the wet season elicited the highest response with $49.7 \%$, followed at a distant second by dry season with $24.3 \%$, next to wet-dry season $(20.9 \%)$ and least being dry-wet season $(5.1 \%)$.

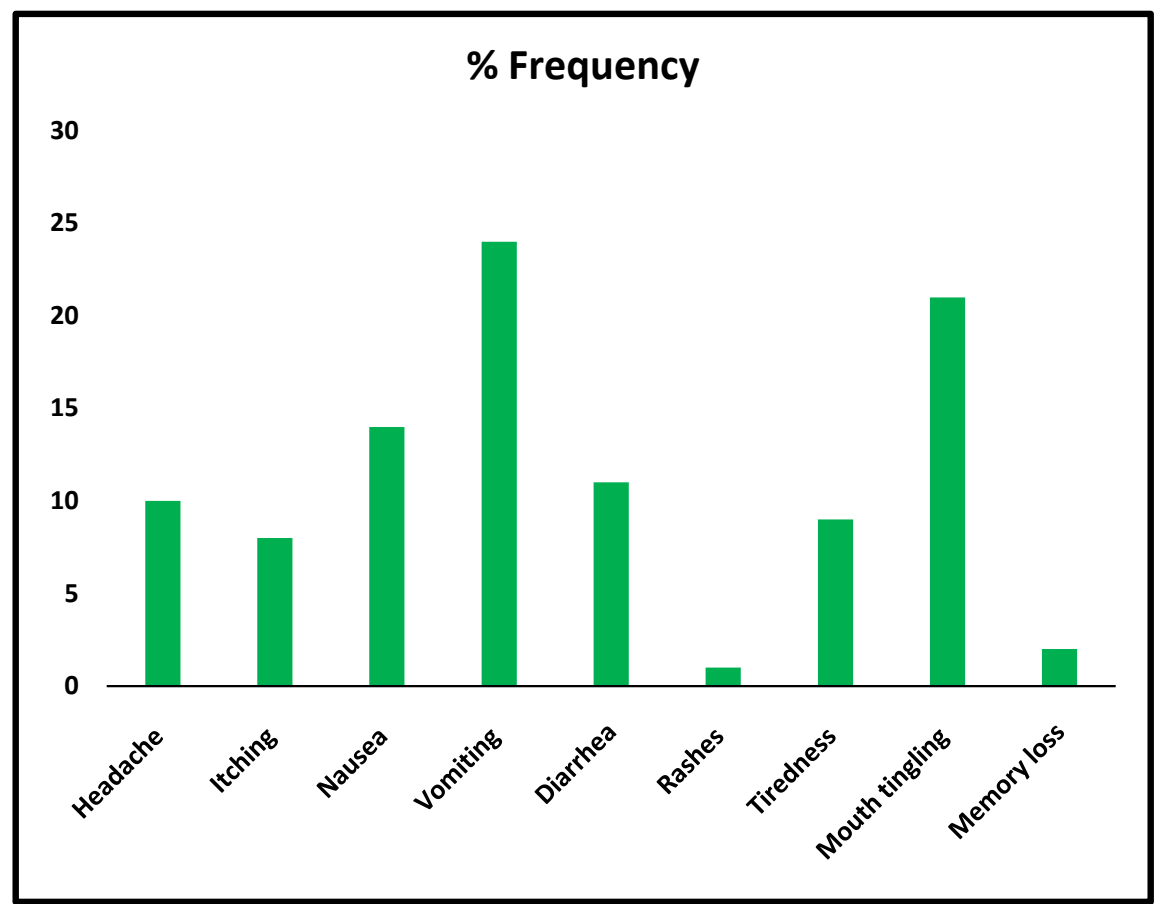

Figure 3. Frequency of occurrence of prevalent human phycotoxin poisoning symptoms in coastal areas. 


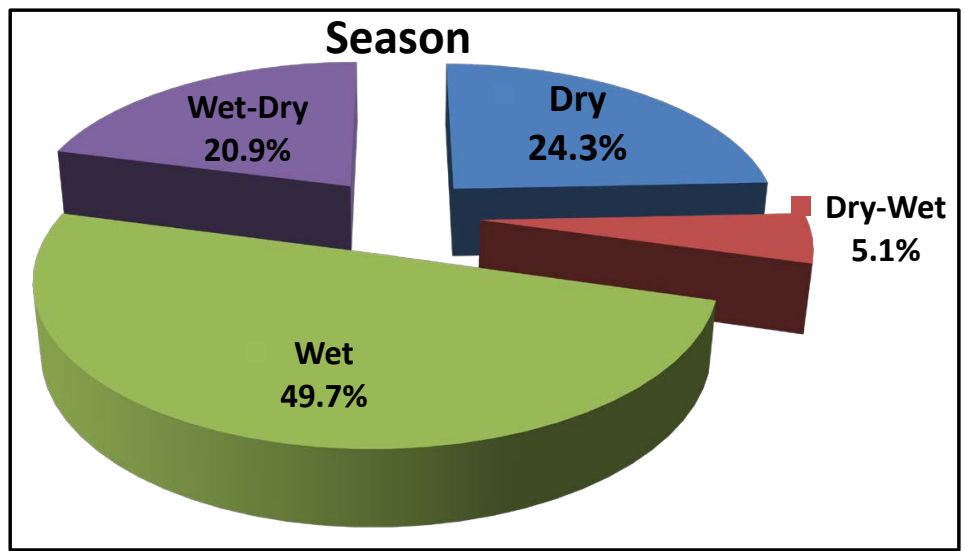

Figure 4. Seasonal occurrence of human phycotoxin poisoning symptoms.

\section{Seafood responsible for symptoms}

Figure 5 shows the distribution of symptoms caused by seafood consumed. Although $67.3 \%$ claimed that they experienced no symptom on consumption of seafood, a sizeable proportion experienced symptoms with their seafood consumption. The highest was shrimps/crayfish, closely followed by crabs and the least being a combination of all seafood (shrimps/crayfish, crab, periwinkle and fish).

Nexus between symptoms from seafood and the particular seafood consumed

Table 1 shows the visible symptoms from seafood and the particular seafood consumed that prompted the visible symptoms. The table shows that Crabs, Periwinkle, fish and a combination of some seafood resulted in substantial symptoms. From the result, it is observed that $3.5 \%$ of the entire respondents who ate crab experienced various symptoms, ranging from vomiting (2.4\%), Body Itching/scratching $(0.5 \%)$ and headache $(0.4 \%)$. For Periwinkle, the symptoms were vomiting (1.7\%), diarrhea (1.2\%) and nausea $(0.8 \%)$.

Of the respondents who consumed fish, $0.4 \%$ had Body itching. Respondents who preferred to consume shrimps/crayfish and crab, and others who consumed shrimps/crayfish, crab and Periwinkle, the most common symptom was Tiredness (1.2\%), while $0.5 \%$ had experienced Diarrhea and many others. However, most respondents claimed to have no preference for any seafood, as they ate all the seafood available with $55.7 \%$, experiencing vomiting as the highest (6.1\%) and $5.8 \%$ presenting with mouth tingling/burning sensation symptoms.

Statistically, the Chi Square analysis, showed that there was a significant relationship (at 95\% confidence limit) between visible symptoms of seafood consumption and the seafood causing the observed symptoms $(\mathrm{p}<0.05)$.

\section{Nexus between symptom from seafood and the season of occurrence}

Seasonal consideration of symptoms as depicted in Table 2 showed that vomiting occurred more in the Dry season (January) with 5.5\%, while headache, Body Itching was predominant in Wet-dry period (October) with (2.8\%). Similarly, Nausea had 3.1\% in Dry season (January) than any season of the year, 


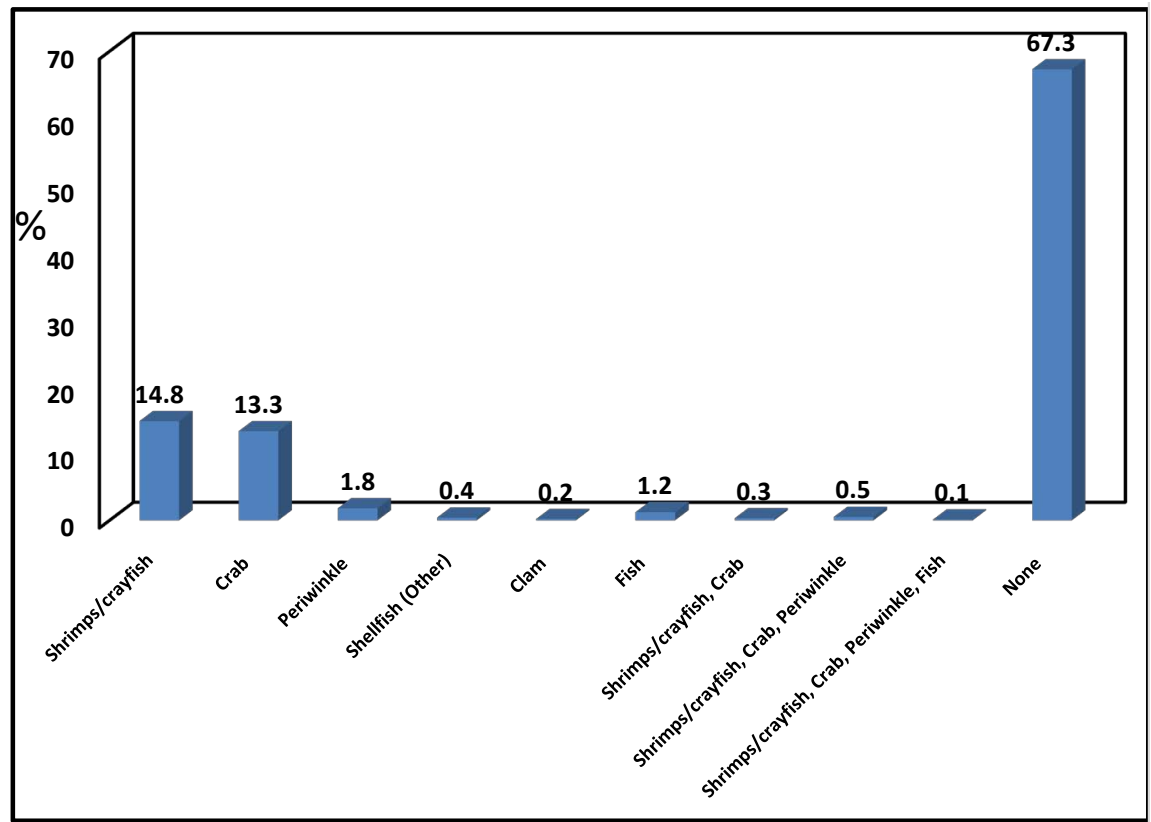

Figure 5. Percentage of Seafood Responsible for human phycotoxin poisoning symptoms.

Table 1. Nexus between the visible symptoms from seafood and the particular seafood.

\begin{tabular}{|c|c|c|c|c|c|c|c|c|c|c|c|}
\hline \multirow[b]{2}{*}{ Symptoms } & \multicolumn{10}{|c|}{ Seafood } & \multirow[b]{2}{*}{ Total } \\
\hline & $\begin{array}{c}\text { Shrimps/ } \\
\text { crayfish }\end{array}$ & Crab & Periwinkle & Shellfish & Clam & Fish & $1 \& 2$ & $1,2 \& 3$ & $1,2,3 \& 6$ & All & \\
\hline Headache & $3(0.3 \%)$ & $4(0.4 \%)$ & $7(0.7 \%)$ & $2(0.2 \%)$ & $3(0.3 \%)$ & $1(0.1 \%)$ & $0(0 \%)$ & $4(0.4 \%)$ & $9(0.9 \%)$ & $16(1.6 \%)$ & $49(5.0 \%)$ \\
\hline Body Itching & $1(0.1 \%)$ & $5(0.5 \%)$ & $8(0.8 \%)$ & $0(0 \%)$ & $0(0 \%)$ & $4(0.4 \%)$ & $0(0 \%)$ & $3(0.3 \%)$ & $5(0.5 \%)$ & $12(1.2 \%)$ & $38(3.9 \%)$ \\
\hline Nausea & $2(0.2 \%)$ & $0(0 \%)$ & $8(0.8 \%)$ & $0(0 \%)$ & $0(0 \%)$ & $2(0.2 \%)$ & $0(0 \%)$ & $3(0.3 \%)$ & $6(0.6 \%)$ & $49(5.0 \%)$ & $70(7.1 \%)$ \\
\hline Vomiting & $1(0.1 \%)$ & $24(2.4 \%)$ & $17(1.7 \%)$ & $1(0.1 \%)$ & $0(0 \%)$ & $2(0.2 \%)$ & $0(0 \%)$ & $7(0.7 \%)$ & $3(0.3 \%)$ & $60(6.1 \%)$ & 115 (11.7\%) \\
\hline Diarrhea & $0(0 \%)$ & $1(0.1 \%)$ & $12(1.2 \%)$ & $1(0.1 \%)$ & $0(0 \%)$ & $0(0 \%)$ & $0(0 \%)$ & $5(0.5 \%)$ & $9(0.9 \%)$ & $24(2.4 \%)$ & $52(5.3 \%)$ \\
\hline Rashes & $0(0 \%)$ & $0(0 \%)$ & $0(0 \%)$ & $0(0 \%)$ & $0(0 \%)$ & $0(0 \%)$ & $0(0 \%)$ & $1(0.1 \%)$ & $0(0 \%)$ & $4(0.4 \%)$ & $5(0.5 \%)$ \\
\hline Tiredness & $0(0 \%)$ & $1(0.1 \%)$ & $0(0 \%)$ & $0(0 \%)$ & $0(0 \%)$ & $0(0 \%)$ & $0(0 \%)$ & $12(1.2 \%)$ & $7(0.7 \%)$ & $25(2.5 \%)$ & $45(4.6 \%)$ \\
\hline $\begin{array}{l}\text { Mouth tingling/ } \\
\text { burning sensation }\end{array}$ & $0(0 \%)$ & $0(0 \%)$ & $0(0 \%)$ & $0(0 \%)$ & $0(0 \%)$ & $2(0.2 \%)$ & $0(0 \%)$ & $3(0.3 \%)$ & $40(4.1 \%)$ & $57(5.8 \%)$ & $102(10.4 \%)$ \\
\hline Memory loss & $0(0 \%)$ & $0(0 \%)$ & $0(0 \%)$ & $0(0 \%)$ & $0(0 \%)$ & $0(0 \%)$ & $0(0 \%)$ & $2(0.2 \%)$ & $3(0.3 \%)$ & $4(0.4 \%)$ & $9(0.9 \%)$ \\
\hline None & $10(1.0 \%)$ & $0(0 \%)$ & $9(0.9 \%)$ & $0(0 \%)$ & $1(0.1 \%)$ & $24(2.4 \%)$ & $4(0.4 \%)$ & 78 (7.9\%) & $75(7.7 \%)$ & $298(30.3 \%)$ & $500(50.8 \%)$ \\
\hline Total & $17(1.7 \%)$ & $35(3.6 \%)$ & $61(6.2 \%)$ & $4(0.4 \%)$ & $4(0.4 \%)$ & 35 (3.5\%) & $4(0.4 \%)$ & $118(12.0 \%)$ & $158(16.0 \%)$ & $549(55.7 \%)$ & 985 (100.0\%) \\
\hline
\end{tabular}

while $2.6 \%$ of the entire respondents were reported to have experience Diarrhea in Wet-dry period (October) than in any other season of the year.

In total, rashes represent the least of the symptoms among all the visible symptoms at the study locations. Of these, $0.4 \%$ was experienced in the month of July (Wet period), while tiredness was highest in July (Wet period), with 3.4\%. Of the entire respondents, and $8.0 \%$ asserted that they experienced Mouth tingling/burning sensation in the month of Wet period (July), making it the month 
Table 2. Nexus between symptoms from seafood and the particular season.

\begin{tabular}{cccccc}
\hline \multirow{2}{*}{ Symptoms } & \multicolumn{4}{c}{ Season } & \multirow{2}{*}{ Total } \\
\cline { 2 - 5 } & $\begin{array}{c}\text { Dry } \\
\text { (January) }\end{array}$ & $\begin{array}{c}\text { Dry-wet } \\
(\text { March })\end{array}$ & Wet (July) & $\begin{array}{c}\text { Wet-dry } \\
\text { (October) }\end{array}$ & \\
\hline Headache & $8(0.8 \%)$ & $1(0.1 \%)$ & $12(1.2 \%)$ & $28(2.8 \%)$ & $49(5.0 \%)$ \\
Body Itching & $4(0.4 \%)$ & $2(0.5 \%)$ & $6(0.6 \%)$ & $26(2.6 \%)$ & $38(3.9 \%)$ \\
Nausea & $31(3.1 \%)$ & $6(0.6 \%)$ & $18(1.8 \%)$ & $15(1.5 \%)$ & $70(7.1 \%)$ \\
Vomiting & $54(5.5 \%)$ & $9(0.9 \%)$ & $24(2.4 \%)$ & $28(2.8 \%)$ & $115(11.7 \%)$ \\
Diarrhea & $4(0.4 \%)$ & $0(0 \%)$ & $22(2.2 \%)$ & $26(2.6 \%)$ & $52(5.3 \%)$ \\
Rashes & $1(0.1 \%)$ & $0(0 \%)$ & $4(0.4 \%)$ & $0(0 \%)$ & $5(0.5 \%)$ \\
Tiredness & $6(0.6 \%)$ & $0(0 \%)$ & $33(3.4 \%)$ & $6(0.6 \%)$ & $45(4.6 \%)$ \\
Mouth tingling/ & $18(1.8 \%)$ & $2(0.2 \%)$ & $79(8.0 \%)$ & $3(0.3 \%)$ & $102(10.4 \%)$ \\
burning sensation & & $1(0.1 \%)$ & $4(0.4 \%)$ & $2(0.2 \%)$ & $9(0.9 \%)$ \\
Memory loss & $2(0.2 \%)$ & $29(2.9 \%)$ & $288(29.2 \%)$ & $72(7.3 \%)$ & $500(50.8 \%)$ \\
None & $111(11.3 \%)$ & $23 \%)$ & $206(20.9 \%)$ & $985(100.0 \%)$ \\
\hline Total & $23(24.3 \%)$ & $50(5.1 \%)$ & $490(49.7 \%)$ & & \\
\hline
\end{tabular}

with the highest symptom of Mouth tingling/burning sensation. Though memory loss was is not a frequently experienced symptom in this study, $0.4 \%$ of the entire respondents experienced it in the month of July (wet period).

The Dry-wet period-March had the least of the visible symptoms, with the highest symptom experienced being just $0.9 \%$ (vomiting), and followed by Nausea with 0.6 Statistical analysis, using Chi Square analysis, at $95 \%$ confidence limit showed that there was significant relationship $(\mathrm{p}<0.05)$ between visible symptoms of seafood consumption and the season of consumption.

\section{Nexus between colour of water and symptoms}

From Table 3, most of the symptoms experienced by the respondents (34.3\%) were from seafood consumed from brown water. Additionally, vomiting (13.2\%), nausea (9\%), headache (3.9\%) and body Itching (2.9\%) were also experienced by respondents who consumed seafood from brown coloured water. For green water colouration, the most common symptoms were vomiting with $1.6 \%$ while the least was Mouth tingling/burning sensation and headache with $0.7 \%$.

The red coloured water had just $0.7 \%$ of all the symptoms, and from these, headache had the highest with $0.4 \%$ and tiredness had $0.2 \%$. From the Chi Square analysis, there was significant relationship $(\mathrm{p}<0.05)$ between visible symptoms and the colour of the water.

\section{Observation and Occurrence of dead seafood in the Coastal Areas.}

Table 4 depicts the observation and occurrence of dead seafood in communities. From the results, $46.3 \%$ of the respondents agreed that they had seen dead seafood around water bodies in their communities. Of these, periwinkle and fish accounted for $36 \%$ and $35.1 \%$ of the dead seafood while shellfish and crab accounted for $16.4 \%$ and $12.1 \%$ of the dead seafood observed respectively. Less 
Table 3. Nexus between symptoms and colour of water.

\begin{tabular}{ccccc}
\hline \multirow{2}{*}{ Symptoms } & \multicolumn{3}{c}{ Water colour } & Total \\
\cline { 2 - 5 } & Brown Water & Green water & Red water \\
\hline Headache & $18(3.9 \%)$ & $3(0.7 \%)$ & $2(0.4 \%)$ & $23(5.0 \%)$ \\
Body Itching & $13(2.9 \%)$ & $6(1.3 \%)$ & $0(0 \%)$ & $19(4.2 \%)$ \\
Nausea & $41(9.0 \%)$ & $4(0.9 \%)$ & $0(0 \%)$ & $45(9.9 \%)$ \\
Vomiting & $60(13.2 \%)$ & $8(1.6 \%)$ & $0(0 \%)$ & $68(14.9 \%)$ \\
Diarrhea & $11(2.4 \%)$ & $6(1.3 \%)$ & $0(0 \%)$ & $17(3.7 \%)$ \\
Rashes & $2(0.4 \%)$ & $0(0 \%)$ & $0(0 \%)$ & $2(0.4 \%)$ \\
Tiredness & $6(1.3 \%)$ & $4(0.9 \%)$ & $1(0.2 \%)$ & $11(2.4 \%)$ \\
Mouth tingling/ & $47(10.3 \%)$ & $3(0.7 \%)$ & $0(0 \%)$ & $50(11.0 \%)$ \\
burning sensation & $4(0.9 \%)$ & $4(0.9 \%)$ & $0(0 \%)$ & $8(1.8 \%)$ \\
Memory loss & $140(30.7 \%)$ & $70(15.4 \%)$ & $3(0.7 \%)$ & $213(46.7 \%)$ \\
None & $342(75.0 \%)$ & $108(23.7 \%)$ & $6(1.3 \%)$ & $456(100.0 \%)$ \\
\hline Total & &
\end{tabular}

Table 4. Visibility of dead seafood in recent times.

\begin{tabular}{cccc}
\hline & Response & Frequency & Percentage \\
\cline { 2 - 4 } Visibility of dead seafood in & Yes & 456 & 46.3 \\
recent times & No & 529 & 53.7 \\
& Total & 985 & 100 \\
& Fish & 160 & 35.1 \\
Types of dead seafood seen & Periwinkle & 164 & 36.0 \\
& Crab & 55 & 12.1 \\
& Can't describe & 2 & 0.4 \\
& Shell fish & 75 & 16.4 \\
& Total & 456 & 100 \\
\hline
\end{tabular}

than one percent $(0.4 \%)$ of the respondents asserted that they could not describe what they saw.

Nexus between massive dead seafood and the habitat of dead seafood

From the result in Table 5, it is observed that one of the most visible dead seafood was fish, as this represented $34.7 \%$ of the entire respondents. Creeks were the dominant habitat where the massive dead seafood was found, followed by the Pond with 9.5\%. However, the most visible dead seafood was the Periwinkle, with $36.2 \%$. Of these, the most visible habitat where these Periwinkles were seen was the Creek with $17.9 \%$, followed by the River with $9.3 \%$.

Crab and the shellfish had $12.1 \%$ and $16.6 \%$ respectively. The most visible place with massive dead crabs according to the respondents was the Creek with $5.5 \%$, followed by the river with $3.5 \%$ and for the shellfish, the most visible place 
Table 5. Nexus between massive dead seafood and habitat of occurrence.

\begin{tabular}{cccccc}
\hline \multirow{2}{*}{$\begin{array}{c}\text { Massive } \\
\text { dead seafood }\end{array}$} & \multicolumn{4}{c}{ Location } & \multirow{2}{*}{ Total } \\
\cline { 2 - 5 } & Creek & Pond & River & Ocean & \\
\hline Fish & $69(15.2 \%)$ & $43(9.5 \%)$ & $32(7.1 \%)$ & $13(2.9 \%)$ & $157(34.7 \%)$ \\
Periwinkle & $81(17.9 \%)$ & $39(8.6 \%)$ & $42(9.3 \%)$ & $2(0.4 \%)$ & $164(36.2 \%)$ \\
Crab & $25(5.5 \%)$ & $11(2.4 \%)$ & $16(3.5 \%)$ & $3(0.7 \%)$ & $55(12.1 \%)$ \\
Can't describe & $0(0 \%)$ & $0(0 \%)$ & $0(0 \%)$ & $2(0.4 \%)$ & $2(0.4 \%)$ \\
Shell fish & $0(0 \%)$ & $6(1.3 \%)$ & $69(15.2 \%)$ & $0(0 \%)$ & $75(16.6 \%)$ \\
Total & $175(38.6 \%)$ & $99(21.9 \%)$ & $159(35.1 \%)$ & $20(4.4 \%)$ & $453(100.0 \%)$ \\
\hline
\end{tabular}

where dead ones occurred was the River $15.2 \%$, followed by the pond with $1.3 \%$. Overall, result from the study showed that the creek was the dominant place dead seafood were found, followed by the river with $38.6 \%$ and the least was the ocean (4.4\%). The highest dead seafood found in the ocean was Fish (2.9\%), followed by Crab $(0.7 \%)$. Of the respondents, $0.3 \%$ chose periwinkle. However, $0.4 \%$ represents people who couldn't describe what they saw.

\section{Nexus between symptoms from seafood and the age of the respondents}

On the age of respondents and the visible symptoms that are associated with the seafood consumed (Table 6), the result shows that respondents within 20 29, 30 - 39 and 40 - 49 years of age were dominant, with $43.1 \%, 25.8 \%$ and $10.8 \%$ respectively. Considering the respondents with no symptoms, these ages corresponded to $19.2 \%, 14.3 \%$ and $6.4 \%$ respectively. On a general note, the study shows that $6.4 \%$ of the entire respondents who experienced mouth tingling/burning sensation are within ages 20 - 29 years, followed Vomiting with 5.2\% under same age.

Of the entire respondents, $2.4 \%$ and $1.9 \%$ under ages 20 - 29 years had experienced headache and Body Itching respectively. This showed that age $20-29$ years had high prevalence for some illness after consuming some selected if not all seafood stated in course of the study. There are other symptoms that are associated with the age and the seafood consumed within the study location (Table 6). Statistically, the Chi Square analysis, at 0.05 level of significance shows that there was significant relationship between visible symptoms of seafood consumption and the age of the respondent.

\section{Discussion}

Seafood is implicated for the various illnesses and the diagnosis of these illnesses is largely based on symptoms presentation and the history of seafood consumption [4]. Different symptoms have been reported by several authors to be triggered or instigated by different causative factors. Partyka [16] for instance reported that numbness, mouth tingling, vomiting diarrhea, among others, have been largely attributed to neurotoxic shellfish poisoning (NSP). Nausea, vomiting, abdominal pain, diarrhea have been ascribed to both Diarrhetic shellfish 
Table 6. Nexus between the visible symptoms from seafood and age.

\begin{tabular}{ccccccc}
\hline \multirow{2}{*}{ Symptoms } & \multicolumn{5}{c}{ Age (years) } \\
\cline { 2 - 7 } & Below 20 & $20-29$ & $30-39$ & $40-49$ & 50 \& above \\
\hline Headache & $15(1.5 \%)$ & $24(2.4 \%)$ & $6(0.6 \%)$ & $4(0.4 \%)$ & $0(0 \%)$ & $49(5.0 \%)$ \\
Body Itching & $7(0.7 \%)$ & $19(1.9 \%)$ & $6(0.6 \%)$ & $3(0.3 \%)$ & $3(0.3 \%)$ & $38(3.9 \%)$ \\
Nausea & $15(1.5 \%)$ & $34(3.5 \%)$ & $15(1.5 \%)$ & $4(0.4 \%)$ & $2(0.2 \%)$ & $70(7.1 \%)$ \\
Vomiting & $18(1.8 \%)$ & $51(5.2 \%)$ & $31(3.1 \%)$ & $10(1.0 \%)$ & $5(0.5 \%)$ & $115(11.7 \%)$ \\
Diarrhea & $10(1.0 \%)$ & $22(2.2 \%)$ & $9(0.9 \%)$ & $8(0.8 \%)$ & $3(0.3 \%)$ & $52(5.3 \%)$ \\
Rashes & $0(0 \%)$ & $5(0.5 \%)$ & $0(0 \%)$ & $0(0 \%)$ & $0(0 \%)$ & $5(0.5 \%)$ \\
Tiredness & $7(0.7 \%)$ & $15(1.5 \%)$ & $17(1.7 \%)$ & $6(0.6 \%)$ & $0(0 \%)$ & $45(4.6 \%)$ \\
Mouth tingling/ & $4(0.4 \%)$ & $63(6.4 \%)$ & $26(2.6 \%)$ & $8(0.8 \%)$ & $1(0.1 \%)$ & $102(10.4 \%)$ \\
burning sensation & & & & & & \\
Memory loss & $5(0.5 \%)$ & $3(0.3 \%)$ & $1(0.1 \%)$ & $0(0 \%)$ & $0(0 \%)$ & $9(0.9 \%)$ \\
None & $91(9.2 \%)$ & $189(19.2 \%)$ & $143(14.3 \%)$ & $63(6.4 \%)$ & $14(1.4 \%)$ & $500(50.8 \%)$ \\
Total & $172(17.5 \%)$ & $425(43.1 \%)$ & $254(25.8 \%)$ & $106(10.8 \%)$ & $28(2.8 \%)$ & $985(100.0 \%)$ \\
\hline
\end{tabular}

poisoning (DSP), caused by Dinophysis and Prorocentrum and Ciguatera Fish poisoning (CFP) caused by Gambierdiscus. These symptoms have been associated with okadaic acid, a major Diarrhetic shellfish poisoning (DSP) very potent toxin. The presence of quantifiable amounts of toxins Okadaic acid and pectenotoxin 2 ascribable to Dinophysis and Prorocentrum species, also found in Nigerian coast, have earlier been confirmed in our previous study [8]. DSP is a human syndrome caused by consumption of shellfish contaminated by toxins produced by Dinophysis and benthic species of Prorocentrum [16] [17] [18]. Consumption of crabs has also been associated with Diarrhetic shellfish poisoning (DSP) [4] [19]. On the other hand, Amnesic shellfish poisoning (ASP) caused by Pseudonitzshia spp is the culprit of gastrointestinal symptoms such as Nausea, vomiting, diarrhea, abdominal cramps, neurological symptoms such as headaches, hallucinations, confusion, short-term memory loss, in addition to seizures, possibility of coma and death [6] [20]. The pennate diatom of the genus Pseudonitzschia (P. delicatissima, P. multiseries, P. cuspidata, P. pungens, and $P$. australis) are generally implicated in the biosynthesis of Domoic Acid (DA) responsible for ASP [6] [20] [21]. Species of Pseudonitzschia have also been found in Nigerian coast [10].

Numbness, tingling, headache, dizziness, nausea, loss of coordination, sensation of floating, muscle paralysis and respiratory failure in severe cases are signs and symptoms of Paralytic shellfish poisoning (PSP) [6] [22]. PSP is caused by harmful microalgae notably Gymnodinium catenatum, Alexandrium catenella, $A$. acatenella, A. fundyense, A. minutum, A. tamarense, $A$. ostenfeldii, Pyrodinium bahamense [21], Cylindrospermopsis raciborskii, Aphanizomenon flos-aquae, Lyngbya spp., Anabaena circinalis ([23] [24]. All these microalgae synthesize saxitoxin responsible for PSP in both marine and fresh water. Most of these species have also been identified from the Nigerian coast [25]. The obser- 
vation of ASP and PSP in the coastal waters of Nigeria earlier reported [11] lends credence to the implication of such syndromes in the corresponding illnesses/symptoms enumerated in this study.

Karena brevis is implicated for throat, nose, eye, respiratory and skin (itching) irritations [26]. It is usually inhaled via marine aerosol. Symptoms of ciguatoxin poisoning are abdominal cramps, nausea, diarrhea, paresthesia of the lips and extremities, reversal of hot and cold sensation, weakness, dizziness, and, in severe cases, acute respiratory failure and coma [27].

Reports of Pulido [19] reveal that abdominal pain and distention, weakness, nausea and vomiting, severe thirst, rapid and weak pulse, and death, in addition to jaundice and shock are also microcystin symptoms in human and mammals. Paralysis, muscle twitching, Body Itching, gasping, convulsions, staggering and death have been associated with neurotoxins (anatoxin-a), while Symptoms of exposure to cylindrospermopsin include nausea, vomiting, diarrhea, abdominal tenderness, pain, and acute liver failure [6].

The respective vectors of these HAB-related illness, according to report of Grattan et al. [4], are reef fish, eels, contaminated farmed fish (CFP); mussels, oysters, scallops, clams, crabs (DSP-okadaic acid); mussels, oysters, scallops, planktivorous fish (NSP); mussels, scallops, clams, puffer fish, crustaceans, gastropods (PSP) and razor clams, oyster, squid, sardines, crabs, lobsters (ASP-domoic acid). These vectors are available and largely consumed by the coastal communities of Nigeria [28]. In general, a myriad of psychological response may accompany these illnesses and these include loss of financial resource, socioeconomic adversity, job opportunity losses, depression, anxiety and substance abuse [4].

As the causative factors of these various illnesses i.e. toxins are odorless, tasteless, and cannot be destroyed by cooking, freezing, or washing seafood [16] [22], and the associated colossal economic losses such as loss of productivity, medical care, debilitation etc., it is therefore incumbent on all to adhere to preventive measures to minimize human and public health risks. It is established that routine clinical tests are unavailable for diagnosis coupled with the absence of known antidote [4]. Reports of Pulido [19] indicates that human intoxications are often misdiagnosed, under-diagnosed, and under-reported to public health authorities, and surmised that regulatory standards, alertness by public health organizations and primary health care providers, in regions with a history of $\mathrm{HABs}$, helps to minimize and manage human health risks; bearing in mind that populations at higher risk of exposure are recreational shellfish pickers, anglers, children, aboriginals in coastal regions. A combination of the above reasons calls for a collaborative and comprehensive management approach, involving policy makers (Federal, State, Local), public health practitioners, and community in tackling the problem of harmful algal symptoms.

\section{Conclusions}

A study of the nature-human phycotoxin poisoning symptoms is very novel in 
Nigeria in general and coastal areas of Nigeria in particular. The advantages of this research are predicated on the pioneer documentation of baseline symptoms, coupled with awareness creation of the various symptoms amongst the coastal communities, whether they have experienced the symptoms or not, in order to be better prepared in case of future manifestation. Knowledge of the symptoms and their causative organisms-harmful algae, will also help the economy of these communities, as their livelihood depends largely on aquaculture/mariculture/farming and harvesting of the vectors (seafoods) of these harmful algae responsible for the toxins and symptoms. This is pertinent in view of the fact that the presence of the toxins/harmful algae responsible for such symptoms has been attested in the coastal areas in our previous studies. Overall, awareness of the symptoms and their causative factors could help in the minimization of the associated psychological, socioeconomic, drug abuse and health (both physical and mental) consequences.

The symptoms enlisted in this study are associated with harmful algal toxins/poisoning. Harmful algal blooms generally have repercussions for public health, commercial fisheries, recreation and tourism and monitoring and management. Usually, monitoring of water bodies for toxins/poisoning and by extension, symptoms, in many regions are primarily reactionary rather than anticipatory. It is therefore pertinent that prevention of illness is of paramount importance in minimizing human and public health risks. Hence routine monitoring of water bodies is suggested for early tracking of occurrence of toxin-producing symptoms, as well as phytoplankton monitoring as an early warning signal for the control of seafood safety, in order to protect the health and economies of coastal communities.

There should be greater public awareness of harmful algal blooms. Effort should be integrative, interfacing current monitoring and management programs with basic research and model development for forecasting systems in both marine and freshwater ecosystems, for proper recognition of these phenomena, understanding of causative factors, prediction and mitigation of their effects.

\section{Acknowledgements}

The authors are grateful to Tertiary Education Trust Fund (TETF) for proving the grant (NRF/TETF 2009) with which the study was done. Professor K. A. Eghafona is appreciated for her assistance with the design of the questionnaire.

\section{Ethics}

The study design and implementation were undertaken with the protection of the volunteers in the study in accordance with the review from an appropriate ethics review committee of University of Benin.

Free and informed consent of the participants and the study protocol was approved by the appropriate Committee for the Protection of Human Participants 
[Research Ethics Committee], by the [University of Benin, Edo State, Nigeria, Protocol \#CMS/REC/2018/144, June 8, 2020].

\section{Conflicts of Interest}

The authors declare no conflicts of interest regarding the publication of this paper.

\section{References}

[1] Glibert, P.M., Anderson, D., Gentien, P., Graneli, E. and Sellner, K. (2005) The Global, Complex Phenomena of Harmful Algal Blooms. Oceanography, 18, 136-147. https://doi.org/10.5670/oceanog.2005.49

[2] Backer, L.C., Manassaram-Baptiste, D., Leprell, R. and Bolton, B. (2015) Cyanobacteria and Algae Blooms: Review of Health and Environmental Data from the Harmful Algal Bloom-Related Illness Surveillance System (HABISS) 2007-2011. Toxins, 7, 1048-1064. https://doi.org/10.3390/toxins7041048

[3] Heil, C.A., Glibert, P.M. and Fan, C.L. (2005) Prorocentrum minimum (Pavillard) Schiller: A Review of a Harmful Algal Bloom Species of Growing Worldwide Importance. Harmful Algae, 4, 449-470. https://doi.org/10.1016/j.hal.2004.08.003

[4] Grattan, L.M., Sailorholobaugh, J. and Morris Jr., J.G. (2016) Harmful Algal Blooms and Public Health. Harmful Algae, 57, 2-8. https://doi.org/10.1016/j.hal.2016.05.003

[5] Carmichael, W.W. and Boyer, G.L. (2016) Health Impacts from Cyanobacteria Harmful Algae Blooms: Implications for the North American Great Lakes. Harmful Algae, 54, 194-212. https://doi.org/10.1016/j.hal.2016.02.002

[6] Trainer, V.L. and Hardy, F.J. (2015) Integrative Monitoring of Marine and Freshwater Harmful Algae in Washington State for Public Health Protection. Toxins, 7, 1206-1234. https://doi.org/10.3390/toxins7041206

[7] Kirkpatrick, B., Fleming, L.E., Squicciarini, D., Backer, L.C., Clark R., Abraham, W., Benson, J., Chenge, Y.S., Johnson, D., Pierce, R., Zaias, J., Bossart, G.D. and Baden, D.G. (2004) Literature Review of Florida Red Tide: Implications for Human Health Effects. Harmful Algae, 3, 99-115. https://doi.org/10.1016/j.hal.2003.08.005

[8] Zendong, Z., Kadiri, M., Herrenknecht, C., Nézan, E., Mazzeo, A. and Hess, P. (2016) Algal Toxin Profiles in Nigerian Coastal Waters (Gulf of Guinea) Using Passive Sampling and Liquid Chromatography Coupled to Mass Spectrometry. Toxicon, 114, 16-27. https://doi.org/10.1016/j.toxicon.2016.02.011

[9] Kadiri, M.O. and Ogbebor, J.U. (2017) Harmful Dinoflagellates in the Gulf of Guinea, Nigeria, West Africa. Harmful Algae News, 55, 6-7.

[10] Kadiri, M.O. and Ogbebor, J.U. (2017) Occurrence and Distribution of Toxigenic Diatom (Pseudonitzschia spp.) in Nigerian Coast, Gulf of Guinea. Proceedings of the 9 th International Toxicology Symposium, Benin, 7-8 September 2017, 66-68.

[11] Kadiri, M.O. and Isagba, S. (2018) Amnesic Shellfish Poisoning (ASP) and Paralytic Shellfish Poisoning (PSP) in Nigerian Coast, Gulf of Guinea. Frontiers in Marine Science, 5, 481. https://doi.org/10.3389/fmars.2018.00481

[12] Kadiri, M.O. and Unusiotame-Owolagba, T. (2020) Modelling Toxin-Producing Algae in the Coastal Waters of Nigeria. Journal of Water Resource and Protection, 12, 74-92. https://doi.org/10.4236/jwarp.2020.121005

[13] Ajuzie, C.C. and Houvenaghel, G.T. (2009) Preliminary Survey of Potentially Harmful Dinoflagellates in Nigeria's Coastal Waters. Fottea, 9, 107-120. 
[14] Kadafa, A.A. (2012) Oil Exploration and Spillage in the Niger Delta of Nigeria. Civil and Environmental Research, 2, 38-51.

[15] Yomere, G.O. and Agbonifoh, B.A. (1999) Research Methodology in the Management and Social Sciences. University of Benin Press, Benin.

[16] Partyka, M. (2019) Harmful Algal Blooms, Unwelcome Visitors to Our Coast. Water $\log , 39,7-9$.

[17] Cembella, A.D. (1989) Occurrence of Okadaic Acid, a Major Diarrhetic Shellfish Toxin, in Natural Populations of Dinophysis spp. from the Eastern Coast of North America. Journal of Applied Phycology, 1, 307-310. https://doi.org/10.1007/BF00003466

[18] Glibert, P.M. (2008) Why the Global Change in Nitrogen Should Concern US. Public Affairs Journal, 4, 47.

[19] Pulido, O.M. (2016) Phycotoxins by Harmful Algal Blooms (HABS) and Human Poisoning: An Overview. International Clinical Pathology Journal, 2, Article ID: 00062. https://doi.org/10.15406/icpjl.2016.02.00062

[20] Horner, R.A., Kusske, M.B., Moynihan, B.P., Skinner, R.N. and Wekell, J.C. (1993) Retention of Domoic Acid by Pacific Razor Clams, Siliqua patula (Dixon, 1789): Preliminary Study. Journal of Shellfish Research, 12, 451-456.

[21] Ajani, P., Harwood, D.T. and Murray, S.A. (2017) Recent Trends in Marine Phycotoxins from Australian Coastal Waters. Drugs, 15, 33.

https://doi.org/10.3390/md15020033

[22] Van Dolah, F.M. (2000) Marine Algal Toxins: Origins, Health Effects, and Their Increased Occurrence. Environmental Health Perspectives, 108, 133-141.

[23] Lucas, B., Dahlmann, J., Erler, K., Gerdts, G., Wasmund, N. and Hummert, C. (2005) Overview of Key Phytoplankton Toxins and Their Recent Occurrence in the North and Baltic Sea. Environmental Toxicology, 20, 1-17. https://doi.org/10.1002/tox.20072

[24] Bittencourt-Oliveira, M.C., Chia, A.M., De Oliveira, H.S.B., Cordeiroaraújo, M.K., Molica, R.J.R. and Dias, C.T.S. (2015) Allelopathic Interactions between Microcystin-Producing and Non-Microcystin-Producing Cyanobacteria and Green Microalgae: Implications for Microcystins Production. Journal of Applied Phycology, 27, 275-284. https://doi.org/10.1007/s10811-014-0326-2

[25] Kadiri, M.O., Ogbebor, J.U. and Omoruyi, O.A. (2016) Spatial Distribution of Some Potentially Harmful Algae in Coastal Waters of Nigeria. Proceedings of the 2nd University of Benin Annual Research Day Conference (UBARD), Benin, 20-23 October 2016, 342-344.

[26] Cheng, Y.S., Zhou Y, Irvin, C.M. Pierce, R.H., Naar, J., Backer, L.C., Fleming, L.E., Kirkpatrick, B. and Baden, D.G. (2005) Characterization of Marine Aerosol for Assessment of Human Exposure to Brevetoxins. Environmental Health Perspectives, 113, 638-643. https://doi.org/10.1289/ehp.7496

[27] Fleming, L.E., Blythe, D. and Baden, D. (1997) Marine Toxin Diseases: Ciguatera Poisoning. Travel Medicine, 1, 1-5.

[28] Oguntade, O.R. Oketoki, O.T., Ukenye, E.A., Usman, B.A. and Adeleke, M.T. (2014) Survey of the Present and Fast Disappearing Fish Species along Two Rivers in the Niger Delta. Journal of Fisheries and Aquatic Science, 9, 352-358. https://doi.org/10.3923/ifas.2014.352.358 


\section{Highlights}

1) Pioneer investigation into harmful algal bloom symptoms in Nigeria, West Africa.

2) Harmful algal bloom symptoms comprising Respiratory problems, Gastrointestinal problems, Neurological problems, Dermatological problems, and Musculo-Skeletal Problems reported.

3 ) The four most frequent symptom are: vomiting (24\%), mouth tingling (21\%), Nausea (14\%), diarrhea (11\%).

4) Correlation between symptoms: and seafood, water colour, habitats, age of respondents.

5) Early warning detection pivoted on preventive actions is recommended. 